\title{
Multi-perspective ICT-toolkit supporting inclusive and sustainable mobility planning in rural areas
}

\author{
Bente Knoll (Author) \\ Büro für nachhaltige Kompetenz (Consultancy for \\ Sustainable Competence) B-NK GmbH, University of \\ Technology Vienna, University of Applied Sciences \\ Technikum Wien, Austria \\ bente.knoll@b-nk.at \\ bente.knoll@tuwien.ac.at \\ knoll@,technikum-wien.at
}

\author{
Petra Busswald (Co-author) \\ akaryon $\mathrm{GmbH}$ \\ Vienna, Austria \\ busswald@akaryon.com
}

\author{
Ralf Dopheide (Co-author) \\ Dipl.-Ing. Ralf Dopheide e.U. \\ Vienna, Austria \\ ralf.dopheide@gartenbox.at
}

\begin{abstract}
The Austrian R\&D-project "AlltagsSPUREN" supports small, mostly rural, municipalities in their efforts to make the local mobility system more inclusive and sustainable. For this purpose, it provides a multi-perspective ICT tools and service kit to be used for activating residents, analysing mobility-related framework conditions and assessing the supposed impact of different planning options. Special focus is set on local experience and the integration of different socio-demographic groups with their specific challenges and mobility demands. The kit supports local decision-makers within the early phase of mobility planning, in order to strengthen knowledge and competence as well as to remove barriers to sustainable and active mobility. While doing this, the project focuses on existing data at local and regional level that can depict mobility conditions comprehensively with minimum effort. This data can also be used for reliable scenarios of future mobility demands.

Index Terms - sustainable and inclusive mobility, active transport modes, rural areas, web-based ICT tool, impact assessment, traffic and mobility model, municipalities
\end{abstract}

\section{INTRODUCTION}

Active modes of transport, such as walking and cycling, exhibit a wide range of ecological, economic and social benefits for individuals as well as for societies. Therefore, they are more sustainable compared to motorized individual traffic (e.g. private car). Public transport also leads to more sustainable mobility conditions, empowerment and social inclusion, especially for people with physical limitations, the young and the old as well as migrants. [7, 8, 18, 19]

\author{
Roswitha Hofmann (Co-author) \\ Dr. Roswitha Hofmann - uebergrenzendenken - Forschung \& \\ wissenschaftliche Beratung e.U., Vienna University of \\ Economics and Business \\ Vienna, Austria \\ office@uebergrenzendenken.at \\ roswitha.hofmann@wu.ac.at
}

\author{
Christoph Link (Co-author) \\ Institute for Transport Studies, University of Natural Resources \\ and Applied Life Science \\ Vienna, Austria \\ Christoph.Link@boku.ac.at
}

\author{
Paul Pfaffenbichler (Co-author) \\ University of Technology Vienna, Austria \\ paul.pfaffenbichler@tuwien.ac.at
}

\section{STATUS QUO AND CURRENT SITUATION}

\section{A. Status quo: Specific needs of different demographic groups and awareness for sustainable modes of transport}

Particularly, people with care-giving responsibilities, children and elderly people and people with few social bonding within the local community have a need for diverse mobility alternatives which consider their specific resources (time, money, abilities etc.). For example, the choice of transport modes differs between people with care responsibilities and notcaregiving people. Care-givers and people in care living in rural areas are often more dependent on car transport, often by others as they are not aware of alternatives or alternatives are in fact missing. [1] Traditional transportation planning approaches strengthen car-dependency by setting a strong focus on motorized individual traffic.

However, the promotion of active and sustainable modes of transport may enable especially these socio-demographic groups to handle their mobility needs more independently and save their resources (e.g. children can go to school by themselves and do not need to be accompanied by their parents). Accompanying trips therefore may be minimized if awareness for sustainable modes of transport is raised. [19] Research on exclusion is still rare and its results are hardly included in mobility projects. An exception is the improved attention given to the needs of physical impaired people. [6] Other excluding aspects related to socio-demographic circumstances and access to resources, for example care-giving responsibilities, are neglected. 
The level of awareness for different modes of transport and types of trips varies in transportation planning. Common travel surveys in Austria, for example, do not adequately examine short trips or complex trip patterns. Short walking trips remain underrepresented due to their low rate of reporting. As a result, these surveys often confirm local decision makers in their point of view that "walking" is not fully worth considering and is not valued as an equitable mode of transport. Consequently, transport-planning decisions are mainly based on data that tend to take into account walking inadequately $[11,17]$.

\section{B. Status quo: Rural areas and their special challenges}

Statistical data show that in the year 2014 2,278 municipalities in Austria have less than 10,000 inhabitants. Altogether they account for 4.6 million inhabitants or over $50 \%$ of the total population in Austria of 8.5 million people. [16]

These mainly peripheral and rural municipalities face special challenges and problems in the contexts of transportation, mobility and basic supply. There is also a strong tendency of centralization of jobs and supply infrastructure in major agglomerations. Thus, the opportunity to satisfy individual requirements (education, shopping, jobs) on a local level vanish resulting in a high need for mobility. However, in the last decades public transport systems have been reduced in a considerable way. As transport infrastructure for cycling and walking is also hardly developed in a sufficient way - and the terrain is often very steep - inhabitants often face a feeling of cardependency. [20]

Demographic change is another aspect, which has to be considered in decision-making and transportation planning processes. By the year 2030, 24\% of the total population in Austria will be older than 65 years. That is an increase of 6 percentage points compared to the year 2012. In rural areas the proportion of elderly people will be even higher. [15] As demographic change affects especially peripheral and structurally weak regions, opportunities have to be found to guarantee independent mobility for the elderly and their participation to social, cultural, political and economic life.

\section{Status quo: Lack of comprehensive approaches}

Active modes of transport were the dominant modes in the last centuries. In the last decades, though, they have become less important, due to societal and structural changes [13]. However, the lack of active mobility in daily life has not only a negative impact on health and environment but also on the identification with the social environment and thus the social cohesion of a municipality. [10] In order to reach the goal of a more sustainable mobility, new ways and comprehensive methods have to be developed.

Although there are already some initiatives and networks in Austria, which support municipalities in transportation planning, few comprehensive approaches can be identified. There are mainly initiatives for specific situations (e.g. improving way to school for children, promoting investments in bicycle infrastructure, etc.). Within the scope of the EU-project PROSPECTS, an easy to understand handbook for sustainable transport was developed for decision makers, which is also available in German language. Moreover, a web-based data- base (KonSULT) was created, giving examples for possible activities for sustainable land use and transport. However, this database is available only in English language and is addressing urban transport planning. A comprehensive analysis of the status quo in the municipalities is not included. [9]

Tools available today are mostly focused on "technical" data analyses with little regard to the diverse target group and their requirements:

- Mobility planning

- Simulation of traffic flows

- Estimation of effects of measures

- Calculation of traffic emissions and follow-up costs

- Accounting systems for mobility

These tools are quite complex and mainly address consultants, planners and scientists, but not decision makers in communities and municipalities. (Nota bene: In Austria municipalities are in charge of most of transport planning responsibilities.) Socioeconomic parameters are widely neglected, therefore not providing comprehensive analysis approaches.

\section{THE AustriAn R\&D-PROJECT “AlLtAGSSPUREN” AT A GLANCE}

The Austrian R\&D-project "AlltagsSPUREN" (loosely translated "everydayTRACES") intends to fill the research gap supporting sustainable and inclusive mobility planning in municipalities with up to 10,000 inhabitants $[4,14]$. The assessment methods developed within the project and implemented in the form of an ICT tools and service kit explicitly focus on inclusive mobility for those in need for specific solutions - who are currently not on the regular agenda of most mobility planning processes in rural areas. $[12,16]$. The web-based tools are used to analyse the local situation and to assess various future scenarios as well as the impact of planning solutions. The kit also includes services that allow to involve the residents at an early stage of the planning process, jointly develop planning solutions and communicate their supposed impacts.

The decision to develop a web-based toolkit was made considering the financial resources available for transportation planning at local level. Appropriate tools have to be easy-tounderstand and to handle, applicable without training lessons and cheap. However, not even in urban areas, participative planning processes can be limited to a web-process. Thus, the web-based analysis and planning tool was extended by the service elements.

The tools also help to identify social, ecological and economic challenges, barriers and success factors for sustainable mobility - thereby addressing the local situation. This is done by combining, processing, comparing and displaying data on local and regional level in a qualitative as well as quantitative manner. This provides a hitherto not available sound basis for mobility planning on local level in municipalities of this size.

The development of the toolkit was accompanied by pilot municipalities with different spatial conditions. The resulting tools are available on the website www.alltagsspuren.at. Currently, these tools refer to the Austrian regional and spatial 
planning situation. Nevertheless, the project team puts much effort in adapting the toolkit also to other regions and countries.

Within the project a multi-disciplinary team has carried out an innovative and creative research and development process. Based on a critical review of the body of literature as well as the planning practice in the day-to-day life of small municipalities in Austria, it developed a comprehensive data set, carried out statistical analysis and developed and tested the toolkit. In order to receive maximum feedback from the supposed users of the tools, namely decision makers and planners in small municipalities, a mix of co-creative methods, such as co-design workshops, were applied.

\section{IV. “ALLTAGSSPUREN” ICT-TOOLKIT - AN OVERVIEW}

The developed toolkit includes three web tools as follows:

\section{A. Communication platform for residents and municipalities}

The website www.alltagsspuren.at collects, shares and thus distributes on its "storytelling platform" mobility-related experiences, wishes and suggestions for mobility solutions posted by residents and visitors of Austrian municipalities. These "mobility stories" can be used in several ways: They can help to initiate planning processes, identify strength and weaknesses during these processes or can feed into a participative process at local and regional level. Moreover, the website offers background information and arguments concerning sustainable mobility. The tool encourages mutual knowledge exchange and fosters capability building in and across communities.

\section{B. Status quo analysis tool for municipalities}

The aim of the analysis tool is to examine and evaluate the current situation of a specific municipality towards its conditions for active or sustainable transport modes like walking, cycling or public transport. For this purpose, information on the local framework conditions is collected with the help of 362 variables in six categories: population, natural conditions, spatial settlement patterns, transport and mobility infrastructure, mobility patterns, and local commitment to sustainability $[2,3$, 5].

In order to follow a multi-perspective approach, it was important to include inclusion-related data such as number of impaired persons and/or number of persons with need for assistance. The data stem from two sources: one part comes from several public sources, such as Statistik Austria, and is prefilled into the web database. The other part has to be entered by the municipality's (administrative) staff.

The collected data are aggregated to 35 "performance indicators". The results are visualised in diagrams (spider charts) and can be compared with reference municipalities. The diagrams provide a clear and intuitive understandable overview of the strengths and limiting factors for the sustainable and active transport modes "walking", "cycling" and "public transport". The results clearly highlight in which areas support measures towards sustainable mobility are necessary.

\section{Scenario design and planning tool for municipalities}

The above mentioned status quo analysis tool is supplemented by an inclusion-oriented scenario tool. For this purpose, 16 types of inhabitants were defined each with specific mobility needs, challenges and opportunities resulting from their living conditions. An example is "pupils with reduced mobility": mobility needs are to meet friends or to go to school, challenges are the missing car driver licence and opportunities are a regular public transport ticket or the opportunity to ride a bike. Another group is "single parents with children younger than school age without car access". The list is open for the elaboration of further types needed in certain cases.

Based on the data collected in the analysis tool, it is analysed if and to which extent the "inhabitant types" can satisfy their mobility requirements based on the local situation of their municipality. Thus, the scenario tool shows how well (or bad) the mobility needs of the different types can be covered.

The results are "scores" for every type and "scores" for each mode of transport. A planning functionality is helping to identify appropriate measures to improve the mobility situation for the specific type and his/her living conditions by calculating the supposed impacts of planning decisions on each score. The resulting performance indicators (municipality level) and scores (type-specific) of the scenario respectively the improved situation can be compared with the status quo.

The toolkit offers the possibility to save the data filled in by the municipality. Therefore, the data collection and the analysed scenarios can also be used in future planning decisions. If analysed measures are implemented, the opportunities of the groups and persons concerned improve. This is desirable first of all from an individual point of view, but also the municipalities benefit from an overall increased level of satisfaction of their inhabitants, by fulfilling their statutory obligation of creating equal living conditions as well as most likely by decreased emigration.

\section{ALGORITHMS AND MODELS WITHIN THE STATUS QUO ANALYSIS TOOL}

A system of indicators to analyse the suitability of a municipality with regard to different modes of transport has been developed:

\section{A. Data}

The data set for the analysis includes quantitative and qualitative local data related, among others, to population, settlement structure, available modes of transport, current modal split, climate, topography, economy, inclusion and sustainability related measures. A quick and cost-effective data collection is important for decision makers in small municipality. Thus, the data stem from public sources or can easily be collected or estimated by the representatives of the municipality. 


\section{B. Indicators}

Up to 362 variables are collected and processed to 35 performance indicators in six categories (population, natural conditions, spatial settlement patterns, transport and mobility infrastructure, mobility patterns, and local commitment to sustainability). As an example, the category "natural conditions" includes the performance indicators "climatic conditions regarding snow", "climatic conditions regarding rain" and "topography". Each performance indicator again consists of one or several variables: The performance indicator "local supply", for example, combines the weighted number of certain shops such as groceries or neighbourhood shops; the performance indicator "local public transport systems" consists of the number of public transport lines, the frequency of departures or the first departure time on a working day.

For each performance indicator, five qualitative classes (AE) were defined with thresholds determined based on a literature review and an analysis of data for a large number of Austrian municipalities. For example, assume that the value of the performance indicator "local supply" for a specific municipality is " 5 " (a small supermarket and several grocery shops). As " 5 " lies within the thresholds of class " $\mathrm{B}$ ", the indicator is assigned to class " $\mathrm{B}$ " helping to clear-cut the positioning of the municipality more intuitively than the absolute quantitative value of the performance indicator.

\section{Impact values and transport modes}

Each indicator furthermore has a specific impact on the probability or opportunity to use the different modes of transport. In the aforementioned example a category value of "B" for "local supply" means a comparable good opportunity to buy food within the municipality. This supports walking and cycling (would result in high impact values of "5" for these transport modes in the table above) since the distances to be covered are small, but does not promote public transport use (lower impact value e.g. "1" or "2"). Out of these impact values of each indicator of a category, the mean values (with equal weights for each performance indicator) are calculated describing the overall opportunities in the municipality to use a certain mode of transport.

An example is given in table 1. The category "spatial settlement patterns" summarises eight performance indicators of which four are shown. The categories' value is the mean value of the performance indicators' values for each mode of transport: the higher the resulting value, the better the local framework conditions for this mode of transport. In this example, the spatial settlement patterns support cycling (impact values: $3,5,5,3)$ most, but are not so supportive for public transport (impact values: $3,1,1,3$ ).
TABLE I. PERFORMANCE INDICATORS AND THEIR IMPACT VALUES

\begin{tabular}{|l|c|c|c|c|c|}
\hline & Value & class & $\begin{array}{c}\text { Impact } \\
\text { value: } \\
\text { Cycling }\end{array}$ & $\begin{array}{c}\text { Impact } \\
\text { value: } \\
\text { Walking }\end{array}$ & $\begin{array}{c}\text { Impact } \\
\text { value : } \\
\text { Public } \\
\text { trans- } \\
\text { port }\end{array}$ \\
\hline $\begin{array}{l}\text { Category: } \\
\text { Spatial } \\
\text { settlement } \\
\text { patterns }\end{array}$ & - & - & $\mathbf{3 , 1 3}$ & $\mathbf{2 , 3 8}$ & $\mathbf{3 , 3 8}$ \\
\hline $\begin{array}{l}\text { Performance } \\
\text { indicator: } \\
\begin{array}{l}\text { Population } \\
\text { density }\end{array}\end{array}$ & 189,42 & $\mathrm{C}$ & 3 & 3 & 3 \\
\hline $\begin{array}{l}\text { Facilities: } \\
\text { Leisure time } \\
\text { and sports }\end{array}$ & 7 & $\mathrm{~A}$ & 5 & 5 & 1 \\
\hline $\begin{array}{l}\text { Facilities: } \\
\text { Local supply }\end{array}$ & 8 & $\mathrm{~A}$ & 5 & 1 & 1 \\
\hline $\begin{array}{l}\text { Facilities: } \\
\text { Childcare }\end{array}$ & 0,004 & $\mathrm{E}$ & 3 & 1 & 3 \\
\hline
\end{tabular}

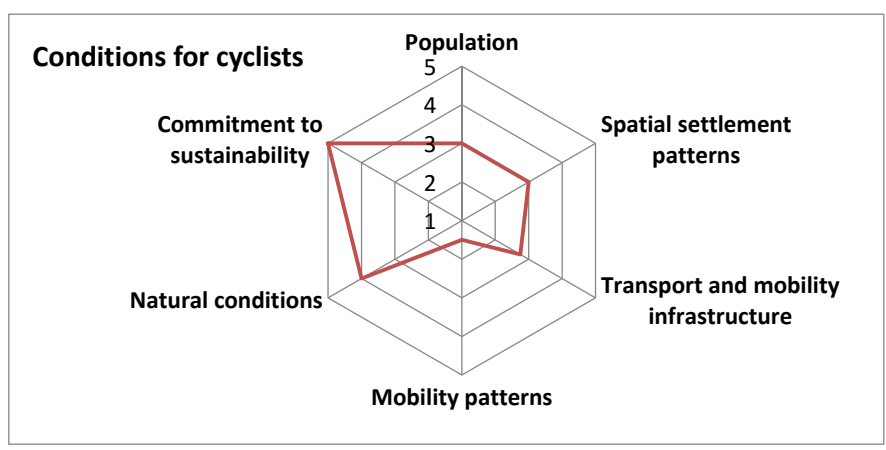

Fig. 1. Spider graph showing conditions for transport mode cycling

The impact factors are also visualised in a spider graph for each mode of transport. Each arm of the spider net stands for one specific category with the category's impact marked. The impact values of each category are combined by a red line conveying an intuitive understanding of the situation for the specific mode of transport: If the local score is close to " 5 ", the category is a success factor respectively providing good conditions for the mode of transport. A low score towards " 1 " and the centre of the net indicates that the category includes barriers and limiting factors for this mode of transport.

\section{MULTI-PERSPECTIVE APPROACH WITHIN THE SCENARIO DESIGN AND PLANNING TOOL}

When developing the scenario and planning tool, the project team's aim was to answer the following questions:

- For which groups of inhabitants with their specific mobility needs and capabilities can the mobility conditions be improved in a sustainable way?

- Which transport mode specific measures support as many types of inhabitants as possible in their mobility behaviour?

- Which transport mode specific measures improve the conditions for a certain type of inhabitants? 
The following method was developed to address the aforementioned questions:

\section{A. Types of inhabitants}

The first step was to define and describe types of inhabitants characterised by their physical abilities, care duties, social relationships and embedment, financial resources and all other aspects determining their living conditions and mobility needs: The importance to reach different facilities and services (e.g. schools, playgrounds, retail shops, employment office, different medical facilities, etc.) and their possibilities to do so.

For the operationalisation in the scenario tool a dataset including this characterization was created for each of the following types of inhabitants:

- School children with physical impairs

- School children and their single parent, no car available

- Children living in patchwork families, multi-residents

- School children living in households with low income, no car available

- Unemployed youngsters without driving licence

- Single parents with children younger than school age without car access

- Adults with low income, not employed, no car available, mentally impaired

- Employed adults with caring duties in the own household, car available

- Adults with caring duties for school children and family members that lives in a special care-home, car available

- Adults aged over 65 years, no mobility impairs, but need for regular medical care, no car available

- Adults with low income and no social relations in the municipality

- Adults with caring duties for babies and low income

- Unemployed adults, no car available

- Employed adults with caring duties for a school child and participating in the local community work

- $\quad$ Retired adults, physically impaired, no car available

- Youngsters with caring duties for family members in the own household

\section{B. Multi-criteria analysis of transport infrastructure and supply}

The second step is the assessment of the transport infrastructure and supply in a municipality (based on data from the analysis tool, arranged by mode of transport) in the style of a multi criteria analysis: A best and worst case value are assigned to each data item (e.g. kilometre of cycling routes, number of bicycle parking lots). These values can be static for all municipalities or dynamically calculated using data from the description of the municipality (e.g. depending on the number of residents, etc. - adapting the best and worst values to the specific situation e.g. size of a municipality). The status quo value of each data item of a specific municipality is then compared with the best and worst values and scaled, by linear interpolation, to a fulfilment score which can best be " 1 " (if the data item equals the best value) or worst be " 0 " when equalling the worst value.

Scores of individual data items can be aggregated to characterise the infrastructure and supply situation for each mode of transport.

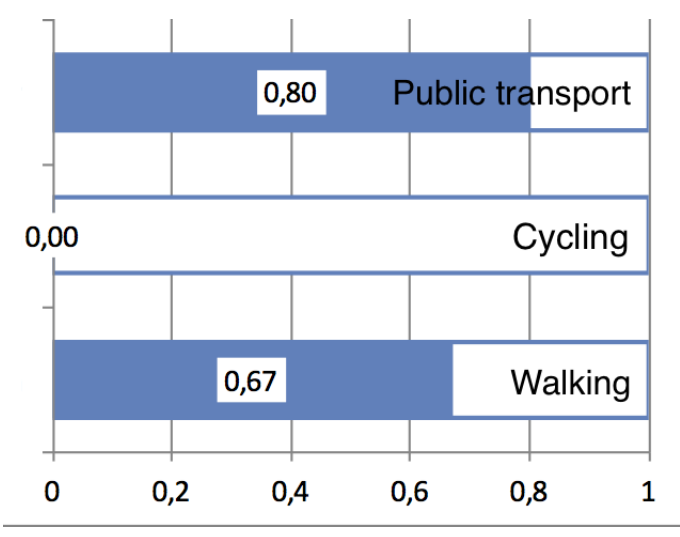

Fig. 2. Second step: Scores for transport modes

\section{Inhabitant type specific assessment}

In a third step the assessment of the transport infrastructure and supply in a municipality (see second step above) is weighted according to the characteristics of types of inhabitants: For example, a person with a physical handicap might not be able to use a certain transport mode (e.g. cycling) or only if it is barrier free or certain groups cannot use certain mobility options due to their financial situation. To reflect these circumstances, each data item is assigned a certain weight for each type of inhabitant. These group specific weights are used to calculate weighted scores resulting in a figure of the same structure as figure 2 above, but with different scores that include the weights of the type of inhabitant in question.

Hence, the results of this analysis provide information on how good mobility needs of certain types of inhabitants can be covered by sustainable mobility options.

\section{Providing measures and recommendations}

The tool supports municipalities by suggesting appropriate measures for improving the situation for a transport mode or an inhabitant type, underlining areas of strength or improving weaknesses. These measures could include to improve the connectives of different modes of transport by improving bike\&ride or park\&ride-facilities or to improve the walking capabilities for persons with limited ability to walk by lower curbs or by building benches.

A bundle of measures then defines a scenario situation. All methods described above can be used to assess the status quo as well as the scenario situation and comparing both to depict the impact and determine the best measures. 


\section{FIELD TRIAL AND LOCALLY ACTIVATION IN PILOT MUNICIPALITIES}

For the project "AlltagsSPUREN" the two Austrian municipalities 'St. Veit in Defereggen' and 'Laa an der Thaya' were selected as pilot municipalities. Municipality representatives as well as municipal staff were involved in the development, the design and the evaluation of the tools. The development process started with a project presentation, proving an overview of the project's aims and approach, namely supporting sustainable and inclusive mobility in rural areas. We discussed with municipal decision-makers the possibilities which can arise by the project for residents, local actors and the municipality.

\section{A. Activation of residents}

To involve the residents, actions providing new impulses and raise the awareness for sustainable modes of mobility were developed and conducted. Schools (teachers and students), local NGOs and associations were engaged to take part and bring in their ideas and inputs for sustainable mobility. For this purpose, the project team has developed interactive actions and workshops suitable for these target groups. In order to reach out to "the wider public" mobility events, "walkshops", as well as "just comfortable get-togethers", within the scope of a narrative mobility café, especially for the elderly were conducted. The narrative mobility cafés for elderly brought essential knowledge about their favourite paths and places and gave an insight on the individual challenges in everyday lives and mobility demands and needs (insights were used in characterizing inhabitant types!). In primary and secondary schools, mobility workshops for different ages were conducted. Children and teenagers visualized and discussed their school trips, and learnt about the history of mobility and about modes of transportation and their environmental impacts. In intergenerational workshops at schools, grandparents reported about their school trips and challenges in former times.

\section{B. Feedback loops}

In order to receive feedback concerning the usability of the website as well as the web-based tools, two methodical approaches were carried out: co-creating workshops and questionnaires.

Within the workshops, decision-makers and mobility representatives provided experiences and knowledge for the tool development with regard to its usability. Feedbacks in terms of visualisation of results, as well as the recommendations proposed, were considered within the fine-tuning of the methods and their implementation into the web tool.

The questionnaires contained several parts, such as the overall impression of the website and the online tools, the comprehensibility of data fields and their explanations as well as the structure and navigation on the platform. Other questions within the scope of the questionnaire addressed the conformity with user expectations, the self-descriptiveness, the controllability and the error tolerance. In addition to the written paperand-pencil questionnaire, an online feedback possibility was implemented directly on the web-interface.

\section{Findings}

Small municipalities often do not have full-time staff familiar with data collecting concerning mobility issues and the handling of web-based tools. Therefore, the provision of assistance in the starting phase and the usability of the analysis tool, the scenario design and the planning tool, are to be considered as key factors. Clearly laid out visualizations of results and recommendations are as important as easy handling.

Overall it can be stated, that the participative approach contributed essentially to a tailor made tool appropriate for the needs of rural municipalities to improve sustainable mobility.

\section{OUTLOOK: LONG-TERM ASSISTANCE SYSTEMS FOR RURAL MUNICIPALITIES AND THEIR INHABITANTS}

Many research projects fear the risk that the results will be hidden in a drawer. To avoid this, the methods developed were implemented in form of web-based tools (instead of only providing guidebooks and reports). To use the tools, there will be a licencing system for municipalities.

The completely new inclusion-orientated approach offering analyses functions per inhabitant types and the possibility to work with the tool in a time and cost efficient way makes the tool and service kit attractive for municipalities. It helps the municipalities to meet actual and future challenges in term of aging societies, migration and social changes by using the respective embedded inhabitant types. The scenario building functionality reveals measures and practical solutions ("next steps") to improve sustainable mobility options on the local level - and delivers appropriate facts and figures in order to support decision making. This makes planning processes and decisions easier, cheaper, quicker and well-founded: According to the approach "planning for as many as possible", municipalities can assess quite easily, how mobility decisions, trafficbased and infrastructural frameworks take effect on different groups of people. Thus, the tool can help make mobility planning inclusive, sustainable, participative, fairer and increase the level of acceptance for decisions among the population.

The methodology included in the tool package - containing a communication platform for residents, a status quo analysis tool as well as a scenario design and planning tool for municipalities - sets new standards towards an inclusive and sustainable future for mobility in rural areas. Nevertheless, the algorithms and the tools can be extended in the future. For example, we intend to detail and expand the performance indicator set and the list of inhabitant types, to elaborate new analyses methods and visual representations of the data and calculations included, to add new aspects respectively data items or to generate methods for aggregated views on regional levels.

\section{ABOUT THE AUTHORS}

Dipl.-Ing. Dr. Bente Knoll works as a self-employed landscape and transport planner, consultant and social media designer. The focus of her professional work as managing director of Büro für nachhaltige Kompetenz (Consultancy for Sustainable Competence) B-NK GmbH is to integrate gender and 
diversity perspectives in urban and transport planning, architecture and mobility as well as in science and technology issues in general. Bente Knoll also holds various teaching assignments at Austrian universities in the field of Gender Studies and Engineering.

Dipl.-Ing. Petra Busswald, holds a degree in 'technical mathematics' and 'technical protection of the environment' from the University of Technology in Graz / Austria. After several years in university projects and at an environmental software company, in 1999 she founded the SME akaryon together with Franz Niederl. akaryon specializes in environmental informatics projects (energy simulation tools, carbon calculators etc.) integrating quantitative sustainability assessment methods in tools for diverse target groups.

Dipl.-Ing. Ralf Dopheide works as a self-employed landscape gardener and consultant for schools (ÖKOLOG-Network Lower Austria) and municipalities. His focus is consultation, research, planning and implementation in the fields of landscape gardening and landscape architecture as well as activities in education and environmental protection.

Mag. Dr. Roswitha Hofmann is sociologist and lecturer at the WU Vienna and the University of Applied Sciences Wiener Neustadt. Her research focus is on diversity and inclusion issues in organizations and sustainability under diversity perspective. She has conducted field studies in Austria and internationally. She has published a number of articles in peer reviewed journals as well as in applied media and edited books. Since 2011 Roswitha Hofmann has been owner of ,uebergrenzendenken“ - Forschung \& wissenschaftliche Beratung e.U.

Dipl.-Ing, Dipl-Georg. Christoph Link works as a researcher at the Institute for Transport Studies, University of Natural Resources and Life Science, Vienna, Austria in several projects in the field of mobility behaviour. His tasks include data collection, data analysis and model development.

Dipl.-Ing. Dr. Paul Pfaffenbichler is Senior Researcher at the Research Center of Transport Planning and Traffic Engineering, Institute of Transportation, Vienna University of Technology.

\section{ACKNOWLEDGMENT}

The project is funded by the Austrian Research Promotion Agency (FFG) and the Federal Ministry of Transport, Innovation and Technology (BMVIT) (Project number 845936).

\section{REFERENCES}

[1] Ahrend, Christine; Herget, Melanie 2012: Umwelt- und familienfreundliche Mobilität im ländlichen Raum. Handbuch für nachhaltige Regionalentwicklung. Technische Universität Berlin. S.12

[2] Buehler, R. 2011: 'Determinants of transport mode choice: a comparison of Germany and the USA'. Journal of Transport Geography, 19(4), 644-657.

[3] Bundesministerium für Verkehr, Innovation und Technologie 2010: 'Der Radverkehr in Zahlen'. Wien.

[4] Bundesministerium für Verkehr, Innovation und Technologie 2016: 'Dokumentation OGD Export: Intermodales Verkehrsreferenzsystem Österreich (GIP.at)', Wien.
[5] Chlond, B., Wirtz, M., Streit, T., Weiss, C., \& Vortisch, P. 2014: 'Mobility Behavior of Season Ticket Holders in Germany'. Paper presented at the Washington DC: presented at the Transport Research Board (TRB) 93nd Meeting.

[6] Gipp, Christoph 2015: Barrierefreie öffentliche Mobilität im ländlichen Raum. In: Ländlicher Raum 01/2015. http://www.iges.com/sites/iges.de/myzms/content/e6/e34/e1021 6/e11837/e11843/e11845/attr_objs11846/IGESInstitutChristoph GippBarrierefreieffentlicheMobilittimlndlichenRaumS31ff_ger. pdf

[7] Herget, Melanie 2013: 'Verkehrsverhalten und Mobilitätsstrategien von Familien in ländlichen Räumen Deutschlands. '

[8] Herry, M., Tomschy, R. 2008: 'Zukünftige Mobilitätsbedürfnisse‘. Grundlagenstudie. Wien.

[9] Institute for Transport Studies, University of Leeds 2015: KonSULT.

http://www.elseviersocialsciences.com/transport/konsult/public/1 evel0/10_hom.htm

[10] Knoflacher, Hermann: Zurück zur Mobilität!: Anstöße zum Umdenken. Ueberreuter, Wien.

[11] Knoll, Bente 2008: Gender Planning. Grundlagen für Verkehrsund Mobilitätserhebungen. VDM Verlag: Saarbrücken.

[12] Knoll, Bente, Spreitzer, Georg, Schwaninger, Teresa, Busswald, Petra, Hofmann, Roswitha, Link, Christoph 2015: 'How to comprehensively - collect and depict data on conditions for sustainable transport in rural areas?: The approach of the Austrian R\&D project "AlltagsSPUREN", in Johannsen, V. K., Jensen, S., Wohlgemuth, V., Preist, C. and Eriksson, E. (eds) EnviroInfo \& ICT4S, Conference Proceedings [Online], Atlantis Press, Amsterdam - Beijing - Paris. Available at http://www.iai.kit.edu/ictensure/site;jsessionid=106E486318A63 27B5099992B8FBA45DF? mod=litdb\&subject=vol\&pid=X32D 8426C\&action=detail (Accessed 11 March 2016).

[13] Nussbaum, Martha 2000: 'Women and Human Development. The Capabilities Approach'. Cambridge.

[14] Statistik Austria 2014: 'Ein Blick auf die Gemeinde'. Available at http://www.statistik.at/web_de/services/ein_blick_auf_die_ge meinde/ index.html (Accessed 26.06.2015).

[15] Statistik Austria 2015: Bevölkerungsprognosen. Available at http://www.statistik.at/web_de/statistiken/bevoelkerung/demogr aphische prognosen/bevoelkerungsprognosen/ (Accessed 2 April 2016)

[16] Statistik Austria 2015: Gemeindegliederung. Available at http://www.statistik.at/web_de/klassifikationen/regionale_gliede rungen/gemeinden/index.html (Accessed 2 April 2016).

[17] Stopher, Peter, Stecher, Cheryl 2006: Travel Survey Methods. Quality and Future Directions. Elsevier: Oxford, Amsterdam.

[18] VCÖ 2003: Gesundheit und Lebensqualität für alle durch bessere Mobilität. In: Mobilität 2020. Trends - Ziele - Visionen. VCÖ Schriftenreihe „Wissenschaft und Verkehr“3/2003. Wien. 30-32.

[19] VCÖ 2009: Mobilität für alle sichern. In: Soziale Aspekte von Mobilität. VCÖ Schriftenreihe „Mobilität mit Zukunft“ 1/2009. Wien. S. 13-17.

[20] VCÖ 2013: Zukunft der Mobilität in der Region. In: „Mobilität mit Zukunft" 3/2013. Wien. 